\title{
PEMANFAATAN PEWARNA ALAMI KULIT BUAH NAGA MERAH SERTA APLIKASINYA PADA MAKANAN
}

\author{
Minda Sari Lubis ${ }^{1}$, Rafita Yuniarti ${ }^{2}$, Ariandi $^{3)}$ \\ Universitas Muslim Nusantara Al-Washliyah ${ }^{1)}$ \\ Universitas Muslim Nusantara Al-Washliyah ${ }^{2)}$ \\ Universitas Muslim Nusantara Al-Washliyah ${ }^{3)}$ \\ mindasarilubis@umnaw.ac.id
}

\begin{abstract}
ABSTRAK
Kulit buah naga merah merupakan limbah hasil pertanian yang mengandung zat warna alami antosianin cukup tinggi. Antosianin merupakan zat warna yang berperan memberikan warna merah yang berpotensi menjadi pewarna alami untuk pangan dan dapat dijadikan alternatif pengganti pewarna sintetis yang lebih aman bagi kesehatan. Metode pelaksanaan yang dilakukan adalah kunjungan ke lokasi mitra, demontrasi pelatihan pembuatan pewarna alami, demontrasi pelatihan pembuatan hasil olahan makanan menggunakan pewarna alami, dan sosialisasi serta pemberian strategi pemasaran produk di jalan Perbatasan Dusun V Desa Bandar Setia, Kecamatan Percut Sei Tuan, Kabupaten Deli Serdang, Provinsi Sumatera Utara, Indonesia. Hasil yang diperoleh dari pengabdian ini yaitu serbuk alami dan hasil olahannya dari kulit buah naga merah. Adapun kesimpulan kegiatan ini setelah dilaksanakan mampu meningkatkan pengetahuan masyarakat tentang bahaya pewarna sintetik, disamping itu masyarakat juga mengenal dan mengetahui tentang bahan pewarna alami yang baik untuk kesehatan, serta dapat menambah pendapatan sampingan masyarakat dengan membuat produk makanan mengunakan pewarna alami kulit buah naga merah.
\end{abstract}

Kata Kunci: Kulit buah naga merah, Serbuk Pewarna alami, Produk Makanan

\begin{abstract}
Red dragon eksocarp are agricultural waste products containing anthocyanin natural dyes is quite high. Anthocyanin is a dye that has the role of providing a red color that has the potential to become a natural dyes agent for food and can be used as an alternative to synthetic dyes that are safer for health. The method of implementation carried out was a visit to a partner location, a demonstration of training in making natural dyes, a demonstration of training in the manufacture of processed foods using natural dyes, and socialization as well as providing product marketing strategies on the Border Road in Dusun V, Bandar Setia Village, Percut Sei Tuan District, Deli Serdang Regency, North Sumatra Province, Indonesia. The results obtained from this comunity dedication are natural powder and processed products from the of red dragon eksocarp. The conclusion of this comunity dedication after being implemented is able to increase public knowledge about the dangers of synthetic dyes, besides that the public also knows about natural dyes that are good for health, and can increase people's side income by making food products using natural dyes of red dragon eksocarp.
\end{abstract}

Keywords: Red dragon eksocarp, natural dye powder, food products 


\section{PENDAHULUAN}

Menurut Peraturan

Pemerintah Nomor 28 tahun 2004, yang dimaksud bahan tambahan pangan (BTP) adalah bahan yang ditambahkan ke dalam makanan untuk mempengaruhi sifat atau bentuk pangan atau produk makanan. Tujuan penambahan BTP secara umum adalah untuk meningkatkan nilai gizi makanan, memperbaiki nilai estetika dan sensori makanan dan memperpanjang umur simpan (shelf life) makanan (Saparinto \& Hidayati, 2006).

Menurut

Peraturan

Menteri Kesehatan Republik Indonesia Nomor 722/Menkes/Per/IX/1998, Bahan tambahan makanan adalah bahan yang biasanya tidak digunakan sebagai makanan dan biasanya bikan merupakan ingredien khas makanan, rnempunyai atau tidak mempunyai nilai gizi, yang dengan sengaja ditambahkan kedalam makanan untuk maksud teknologi (termasuk organoleptik) pada pembuatan, pengolahan, penyiapan, perlakuan, pengepakan, pengemasan, penyimpanan atau pengangkutan makanan untuk menghasilkan atau diharapkan menghasilkan (langsung atau tidak langsung) suatu komponen atau mempengaruhi sifat khas makanan tersebut. Bahan tambahan pangan yang mencegah atau menghambat permentasi, pengasaman, atau penguraian lainnya terhadap pangan yang disebabkan mikroorganisme (MS Lubis, 2019).

Pewarna merupakan salah satu bahan tambahan pangan yang banyak digunakan. Secara umum ada dua jenis bahan pewarna yaitu pewarna sintetis dan pewarna alami (Paryanto, dkk. 2013). Zat pewarna sintetis merupakan zat warna yang berasal dari zat kimia, yang sebagian besar tidak dapat digunakan sebagai pewarna makanan karena dapat menyebabkan gangguan kesehatan terutama fungsi hati di dalam tubuh. Pewarna alami merupakan zat warna yang berasal dari ekstrak tumbuhan (seperti bagian buah, daun, bunga, biji), hewan atau dari sumber-sumber mineral yang telah digunakan sejak dahulu sehingga sudah diakui bahwa aman jika masuk kedalam tubuh (Cahyadi. 2009). Pewarna alami yang berasal dari tumbuhan mempunyai berbagai macam warna yang dihasilkan, hal ini dipengaruhi oleh beberapa faktor, seperti jenis tumbuhan, umur tanaman, tanah, waktu pemanenan dan faktor-faktor lainnya.

Penambahan pewarna sintetik pada makanan sebenarnya bukanlah suatu larangan, namun apabila zat pewarna yang digunakan adalah pewarna yang tidak lazim untuk makanan, inilah yang membahayakan kesehatan. Untuk mengatasi permasalahan tersebut, maka perlu dilakukan penelitian untuk mencari alternatif bahan alam yang berpotensi dapat digunakan sebagai zat pewarna ( Sri, 2016).

Buah naga (Dragon Fruit) merupakan buah pendatang yang banyak digemari oleh masyarakat karena memiliki khasiat dan manfaat serta nilai gizi cukup tinggi(Astuti, dkk. 2012). Pada umumnya buah naga dikonsumsi dalam bentuk segar sebagai penghilang dahaga. Selain itu, buah naga juga sebagai salah satu jenis buah-buahan yang berkhasiat menurunkan kadar kolesterol darah yang tinggi, pencegah penyakit tumor, kanker, melindungi kesehatan mulut, 
pencegah pendarahan, pencegahan dan mengobati keputihan, meningkatkan daya tahan tubuh, menormalkan sistem peredaran darah, menurunkan tekanan emosi, menetralkan toksin (racun) dalam tubuh, menurunkan kadar lemak, menguatkan fungsi otak, melancarkan proses pencernaan, menyehatkan mata, menguatkan tulang dan pertumbuhan badan, menjaga kesehatan jantung, memperhalus kulit wajah, dan mengobati sembelit (Cahyono, 2009).

Jenis buah naga yang telah dibudidayakan ada empat, antara lain Buah Naga Daging Putih (Hylocereus undatus), Buah Naga Daging Merah (Hylocereus polyrhizus), Buah Naga Daging Super Merah (Hylocereus costaricensis), dan Buah Naga Kulit Kuning Daging Putih (Selenicereus megalanthus) (Winarsih,

2007). Bagian dari buah naga $30-$ $35 \%$ merupakan kulit buah namun seringkali hanya dibuang sebagai sampah . Kulit buah naga mengandung zat warna alami antosianin cukup tinggi (Astuti, dkk.

2012). Antosianin merupakan zat warna yang berperan memberikan warna merah berpotensi menjadi pewarna alami untuk pangan dan dapat dijadikan alternatif pengganti pewarna sintetis yang lebih aman bagi kesehatan (Citramukti, 2008).

Penambahan warna pada makanan bertujuan untuk memperbaiki penampakan makanan sehingga meningkatkan daya tarik, memberi informasi yang lebih baik kepada konsumen tentang karakteristik makanan, menyeragamkan warna makanan, menstabilkan warna, menutupi perubahan warna selama proses pengolahan, dan mengatasi perubahan warna selama penyimpanan (Basrah 1987).

Ada beberapa masalah yang dihadapi mitra dan orangtua siswa TK Ar- Rahman di Jalan Perbatasan Dusun V Desa Bandar Setia, Kecamatan Percut Sei Tuan, Kabupaten Deli Serdang, Propinsi Sumatera Utara. Salah satunya adalah kurangnya pengetahuan masyarakat tentang bahaya penggunaan bahan pewarna sintetik, banyaknya masyarakat yang menggunakan pewarna sintetik dalam makanan, banyaknya makanan yang beredar di pasaran menggunakan bahan pewarna sintetik, masyarakat belum mengetahui bahwa kulit buah naga merah dapat digunakan sebagai bahan pewarna alami yang aman dalam tubuh dan bermanfaat bagi kesehatan.

Tujuan kegiatan pengabdian ini untuk miningkatkan kesadaran masyarakat bahwa bahaya penggunaan zat pewarna sintetik, meningkatkan pengahasilan tambahan bagi masyarakat dalam memproduksi makanan dengan zat pewarna alami kulit buah naga merah yang bermanfaat bagi kesehatan, memberikan konstribusi ilmiah melalui publikasi di artikel tentang pemanfaatan pewarna alami kulit buah naga merah serta aplikasinya pada makanan. Target luaran PKM ini adalah laporan kegiatan dan artikel pada pertemuan ilmiah.

\section{METODE PELAKSANAAN}

Metode pelaksanaan pengabdian kepada masyarakat ini adalah dengan melakukan penyuluhan kepada masyarakat 
mengenai bahaya penggunaan pewarna sintetik yang terdapat dalam makanan, dan penyuluhan tentang pewarna alami dari kulit buah naga merah serta aplikasinya pada makanan khususnya kue basah, dimana lokasi pengabdian masyarakat ini dijalan Perbatasan Dusun V Desa Bandar Setia, Kecamatan Percut Sei Tuan, Kabupaten Deli Serdang, Propinsi Sumatera Utara. Metode pelaksanaan kegiatan ini dilakukan dengan beberapa tahapan sebagai berikut :

1. Kunjungan ke lokasi mitra

2. Demontrasi pelatihan pembuatan pewarna alami

3. Demontrasi pelatihan pembuatan hasil olahan makanan menggunakan pewarna alami

4. Sosialisasi serta pemberian strategi pemasaran produk.

\section{HASIL DAN PEMBAHASAN}

Kegiatan pengabdian ini dilakukan terlebih dahulu melakukan survey pendahuluan dan koordinasi Pengurus TK Ar Rahman yang bernama Ibu Yanti Mala Dewi dan orang tua siswa TK Ar Rahman sekaligus tim pengabdi melakukan pelatihan pembutan pewarna alami dari kulit buah naga merah, dimana sebelumnya tim pengabdi telah memberikan informasi tentang bahaya pewarna sintetik pada makanan.

$$
\text { Kegiatan pengabdian }
$$

masyarakat ini telah dilakukan dengan memberikan penyuluhan dan pelatihan pembuatan pewarna alami serta hasil olahannya seperti kue basah. Pembuatan pewarna alami yang menggunakan bahan kulit buah naga merah dilakukan dengan prosedur sebagai berikut: sebanyak $1000 \mathrm{~g}$ kulit buah naga merah, dimasukkan kedalam juicer lalu dihaluskan. Selanjutnya dipisahkan antara residu dan sarinya, sari diperoleh sebanyak $500 \mathrm{ml}$. Kemudian dipanaskan diatas hot plate pada suhu $40 \mathrm{oC}$ sambil diaduk sampai $1 / 3$ bagian, lalu pindahkan kedalam lumping ditambahkan sedikit demi sedikit amylum manihot sebanyak $250 \mathrm{~g}$ digerus sampai homogen, hingga diperoleh serbuk pewarna kulit buah naga merah. Serbuk pewarna alami yang diperoleh diaplikasikan pada makanan basah, salah satunya adalah puding agar. Prosedur kerja dalam pembuatan puding agar adalah sebagai berikut: kedalam panci yang berisi air $800 \mathrm{ml}$, masukkan1 bungkus agar -agar plain, 100 gram gula pasir. Lalu diaduk sampai tercampur rata. Kemudian rebus bahan yang sudah dicampur didalam panic hingga sedikit mendidih dan dibagi menjadi dua bagian. Bagian I masukkan 5 gram serbuk kulit buah naga merah, aduk rata tunggu sampai mendidih dan matang. Bagian II masukkan 10 gram serbuk kulit buah naga merah, aduk rata tunggu sampai mendidih dan matang. Kemudian tuang kedalam cetakan, biarkan sampai dingin.

Setelah dingin potong agaragar dan siap untuk dikonsumsi. Pewarna alami yang telah dibuat dapat dikemas dan dilakukan Labelling sehingga dapat dipasarkan. Hal ini bertujuan untuk menambah penghasilan sampingan mitra kerja sama. Pelaksanaan pengabdian masyarakat ini diharapkan memberikan manfaat pada orang tua siswa TK Ar Rahman di Jalan Perbatasan Dusun V Desa Bandar Setia, Kecamatan Percut Sei Tuan, Kabupaten Deli Serdang, Provinsi Sumatera Utara, Indonesia, dimana 
meningkatkan pengetahuan masyarakat tentang bahaya pewarna sintetik dan pengetahuan tentang daya guna limbah kulit buah naga merah. Selain itu kegiatan ini juga dapat meningkatkan produktifitas masyarakat.

\section{KESIMPULAN}

Adapun kesimpulan kegiatan ini setelah dilaksanakan mampu meningkatkan pengetahuan masyarakat tentang bahaya pewarna sintetik, disamping itu masyarakat juga mengenal dan mengetahui tentang bahan pewarna alami yang baik untuk kesehatan, serta dapat menambah pendapatan sampingan masyarakat dengan membuat pewarna makanan mengunakan pewarna alami kulit buah naga merah.

\section{REFERENSI}

Astuti, P. H dan Asri, R.2012.

Pemanfaatan Kulit Buah Naga (Dragon friut) Sebagai Pewarna Alami Makanan Pengganti Pewarna Sintetis. Semarang. Jurnal Bahan Alam Terbarukan ISSN 2303-0623.

Basrah A. 1987. Zat Warna dan Pemakaiannya dalam Industri Pangan. Jakarta (ID): Risalah seminar bahan tambahan kimiawi.

Cahyadi W. 2009. Analisis dan Aspek Kesehatan Bahan Tambahan Pangan. Jakarta (ID): Bumi Aksara.

Cahyono, B. 2009. Buku Terlengkap Sukses Bertanam Buah Naga. Pustaka Mina, Jakarta.

Citramukti, I., (2008), Ekstraksi dan Uji Kualitas Pigmen
Antosianin Pada Kulit Buah Naga Merah (Hylocereus costaricensis), (Kajian Masa Simpan Buah dan Penggunaan Jenis Pelarut), Skripsi Jurusan THP Universitas Muhammadiyah Malang, Malang.

MS Lubis, RA Syahputra dan G Ritonga. 2019. "PKM Pembuatan Saus Menggunakan Buah Andaliman Sebagai Pengawet Alami". Prosiding Seminar Nasional Hasil Pengabdian. Vol.2 No.1. Halaman: 505509.

Paryanto P, Hermiyanto H, Sanjaya DS. 2013. Pembuatan Zat Warna Alami dari Biji Kesumba dalam Bentuk Konsentrat Tinggi untuk Pewarna Makanan. METANA. 9(2): 41-45.

Peraturan Pemerintah Republik Indonesia Nomor 722/Menkes/Per/IX/1998 tentang Bahan Tambahan Makanan.

Peraturan Pemerintah Republik Indonesia Nomor 28 Tahun 2004 tentang Keamanan, Mutu dan Gizi Pangan.

Saparinto, C dan Hidayati, D. 2006. Bahan Tambahan Pangan. Penerbit kanisius. Yogyakarta. Halaman : 7-8

Sri, S.H. 2016. Optimasi Pengambilan Antosianin dari Kulit Buah Naga Merah (Hylocereus polyrhizus) Sebagai Pewarna Alami pada Makanan. Jurnal Chemica Volume 3, Nomor 2, ISSN: 2355-8776. Halaman : 39-45.

Winarsih, S., (2007), Mengenal dan Membudidayakan Buah Naga, Semarang: CV Aneka Ilmu. 